\title{
Integration of Occupational Health and Safety into Lean Manufacturing: Quebec Aeronautics Case Study
}

\author{
Amine Sakouhi, Sylvie Nadeau \\ Department of Mechanical Engineering, École de technologie supérieure, Montréal, Canada \\ Email: amine_sako@hotmail.com,Sylvie.Nadeau@etsmtl.ca
}

How to cite this paper: Sakouhi, A. and Nadeau, S. (2016) Integration of Occupational Health and Safety into Lean Manufacturing: Quebec Aeronautics Case Study. American Journal of Industrial and Business Management, 6, 1019-1031.

http://dx.doi.org/10.4236/ajibm.2016.611097

Received: October 4, 2016

Accepted: November 1, 2016

Published: November 4, 2016

Copyright $\odot 2016$ by authors and Scientific Research Publishing Inc. This work is licensed under the Creative Commons Attribution International License (CC BY 4.0).

http://creativecommons.org/licenses/by/4.0/

\begin{abstract}
The literature remains divided the ideal conditions for integration of occupational health and safety (OHS) into continuous improvement initiatives based on the principles of lean manufacturing. Few significant results and little documentation exist on the effectiveness, sustainability and the degree of integration. This paper outlines some possible explanations for the non-success of this integration and examines the hypothesis that integration is unsuccessful when the lean-based improvements themselves suffer from sustainability issues. This research project addressed the case of a Québec manufacturing company and focused on musculoskeletal injury (MSI). Twenty-four employees participated in the study for two months. Corporate documentation was analyzed. Individual interviews were used to document workers' perception of their work environment. Continuous improvement interventions were observed to identify possible risks of MSI, and obtain a general portrait of OHS and continuous improvement in this company. The majority of the employees surveyed believed that the continuous improvement initiatives were short-lived. They also reported they experienced MSI-related discomfort following organizational changes. Examination of several initiatives showed that results were not maintained over time. The integration of OHS into continuous improvement is not systematic. When this integration is apparent, OHS goals are not always met and are rarely subject to monitoring. Taking OHS into consideration, implementing lean principles does not directly guarantee a reduction in cases of MSI. The integration of OHS into continuous improvement activities is reflected in the systematic consideration of OHS in driving lean improvements. The results of this project will help to develop a better approach to the implementation of lean to improve this integration in our industries.
\end{abstract}




\section{Keywords}

Lean Manufacturing, Continuous Improvement, Musculoskeletal Injuries, Sustainability

\section{Introduction}

Coined in 1987 by a research team at the Massachusetts Institute of Technology, the term lean was used to describe the Toyota production system. Lean manufacturing now refers to a socio-technical system, of which the main objective is to eliminate waste caused by variability associated with customers, suppliers or internal operations. The undeniable success of this system over the subsequent two decades created huge interest in understanding its principles. Dozens of books continue to be published annually on this management method, in addition to thousands of research articles that have been published on the subject. In spite of the attention that has been given to understand and apply the lean approach around the world, its impact on occupational health and safety (OHS) remains largely unknown [1] [2] [3] [4]. A great debate is taking place to identify the OHS consequences of implementing lean manufacturing. The present article weighs in on this debate by attempting to shift it to evaluate the multitude of approaches to implementing lean production rather than the lean management system itself. This perspective is novel and appears to address a subject area, in which knowledge is lacking [5] [6]. Many studies in this subject area have addressed the impact of organizational changes on OHS. A great debate on the consequences of applying the lean philosophy in industry continues to rage [1] [2] [3] [4] [7]. However, over twenty years have passed since the first introduction of lean implementation in Ameri$\mathrm{ca}$, and there is still no clear consensus regarding the elements of lean that have the greatest impact on OHS [2] [8].

This situation leads us to ask the following questions: Is the lean philosophy threatening the worker efficiency/wellbeing balance? Do we need to re-examine the lean model before integrating it into our industries? The goal of the present study was thus to explore the impact of the chosen approach to implementing lean manufacturing, particularly in terms of sustainability as reflected by the incidence of musculoskeletal injury (MSI) among workers. In order to achieve this, a single corporate case was examined.

\section{Modeling the Integration of Lean Manufacturing and OHS}

Several published studies describe attempts to model lean manufacturing and its integration with OHS. Bakker et al. [9] and Demerouti et al. [10] [11] were the first to introduce the JD-R (job demand/resources) model, of which the central theory is that burnout, regardless of the type of work involved, sets in when job demands become substantial while resources are limited or subject to uncertainty. This model has not been adopted for application in lean industries. These complex and dynamic industries 
tend to use resources in ways (interacting with manufacturing chain parameters) that have both positive and negative effects (the latter sometimes uncontrolled) on worker wellbeing. We note also that the lean concept itself does not imply working conditions that necessarily have an adverse impact on OHS. The model of Bateman [12] and Bateman and David [13] comprises "a succession of levels of sustainability" designated A to E. More precisely, these levels are used to describe "the different stages of an improvement activity and... the different outcomes in terms of sustainability at each stage" [12]. Only initiatives at level A are continuous improvement activities, while level B initiatives can evolve into such activity [12]. The other levels correspond to temporary improvements that do not withstand the routine or the variability of daily production. Both studies by Bateman and David [13] reached conclusions regarding the factors that constitute an A level initiative and thus improve the sustainability of its results. Two events assigned to the same class of sustainability will have effects of similar sustainability. However, this model does not provide tools to classify the sustainability of operational changes. Measurement of performance allows a company to emphasize the goal that it is attempting to achieve through its stated objectives and to encourage staff to maintain its effort. Measuring the improvement achieved is a significant part of maintaining it. Studying this principle, Glover et al. [14] and Farris et al. [15] devised a way to measure the sustainability of a result, based on respectively 65 and 56 improvement initiatives. The results of both studies indicated the factors that had the most influence on the continued commitment of staff to implementing a process improvement: work area characteristics, characteristics of the continuous improvement initiative, and characteristics associated with post-implementation trends. The model of Glover et al. [14] incorporates variables compiled from 152 publications and describes their influence on the sustainability of lean-based improvements. Although the influence of the various factors is apparent, the degree of influence of each remains the subject of debate. In general, the sustainability of an improvement is as important as the reform itself. Sustainability is fundamental to organizational development and improvement [16]. However, the literature contains reports of difficulties with the long-term maintenance of improvements obtained by applying lean principles [14] [17]. From an OHS perspective, change is helpful only if results are sustainable, and research in this field is becoming more and more focused on sustainability. Integrating OHS into continuous improvement of performance is a retroactive exercise in the sense that each initiative should be designed to improve both production and occupational wellbeing.

Using different approaches and models, several researchers have attempted to evaluate the sustainability of the results of continuous improvement initiatives undertaken by businesses. Few have examined the effects that sustainability itself might have on internal elements other than worker performance and commitment [14]. Based on theory and previous research on lean manufacturing, OHS, process improvement, continuous improvement, risk analysis, organizational health, and sustainability, we hypothesize that integration of OHS into a continuous improvement initiative is bound to fail when the initiative itself does not adhere to a sustainable approach to development and acci- 
dent/injury/ illness prevention.

\section{Research Methodology}

The case study concerned a manufacturing company in the aeronautical industry. The company is a division of a group that enjoys complete autonomy regarding the choice of improvements to pursue. The choice of improvement activity is made in consideration only of its relevance to the continued improvement plan previously established by the company. This plan reflects the goals and overall vision of the group. Details of initiatives (dates, objectives, outline, participants, etc.) are decided internally within the company. Lean manufacturing has been implemented gradually in the company, and this has allowed it to acquire ever-increasing maturity and mastery of the techniques. The integration of OHS into continuous improvement activities became reality in this company thanks to:

- Using lean techniques such as kaïzen and $5 \mathrm{~S}$ events in the carrying out of OHS interventions.

- Adding an OHS goal to the list of objectives in lean-inspired projects.

- Taking into account undocumented OHS risks in carrying out lean-inspired projects. Doing so depended exclusively on the participants and their level of authority.

In spite of this, integration is not always apparent and certainly does not adhere to rules or standards. For the past two years, since the implementation of an annual progress plan, management has been defining OHS objectives and lean-inspired activities have been assigned to these objectives in support of their achievement. Establishment of a more formal integration of OHS with continuous improvement activities is envisaged. The population of interest consisted of the 500 production employees of the company. Following an oral presentation, open to all, on the various aspects of the study (objectives, procedure, benefits, etc.) and signatures of a consent form, $24 \mathrm{em}-$ ployees ( $66 \%$ men, $34 \%$ women, which is representative of the company's population) agreed to voluntarily participate to the study, as École de technologiesupérieure's research ethics committee requires. Two groups were identified: those with experience in lean manufacturing and those without such experience. The term "with experience in lean manufacturing" means having participated in at least one lean project and having received at least eight hours of instruction on lean manufacturing. About $30 \%$ of the production employees were in the first group. About $80 \%$ were working on production lines that had been targets of lean projects prior to the study.

The dependent variable in this study was the persistence (incidence over time) of MSI among workers directly concerned by the continuous improvement initiative. According to the National Institute for Occupational Safety and Health and the National Research Council of Canada [18] MSI is a generalized health issue in the work environment. The 2011 Quebec National Public Health Institute reported 2.4 million workdays lost annually due to MSI in the province between 2000 and 2009. This problem is exacerbated in businesses that practice lean manufacturing [2] [19] [20] [21]. We 
therefore chose this variable to operationalize OHS problems in the workplace

Several means of data collection were used (Figure 1). Examination of corporate documents and information systems provided a general portrait of OHS status (structure of administrative procedures and policies regarding preventive measures) as well as the type of initiatives undertaken in the quest for continuous improvement (structure, assignment of roles, milestones, training, tools and techniques, etc.). This analysis also allowed collection of data on effectiveness and efficiency during the post-implementation periods as well as identification of trends following selected continuous improvement initiatives. Semi-structured interviews of participants (30 min for each participant) were then conducted to draw attention to possible random events that might have gone undetected using other means of collecting data on unofficial organizational practices. Interviews facilitate the ownership and sharing of information on continuous improvement initiatives and OHS preventive interventions. The interviews focused on two main themes: continuous improvement and risk of MSI. The response rate obtained in the interviews was $100 \%$, due mainly to completion of the surveys during the direct interview and to explanation of each question as the participant answered it. Twenty-one percent of the participants had already participated in continuous improvement initiatives. Of these, $75 \%$ had only a single experience. Only one of the participants had piloted a continuous improvement project. Finally, direct observations of working situations and ongoing continuous improvement initiatives were conducted to collect information about the difficulties and facilitators of improving productivity, quality OHS conditions. More precisely, six lean interventions (three-to-five-day kaïzen events, using lean techniques like kanban, 5S, SMED and 5 whys) were observed in this study. This study is thus based on a triangular approach to data collection (document analysis, semi-structured interview and observations). Interviews provided the opportunity to gather information on participants' perceptions of their work environment beyond the limited scope of the question. Direct observation and document analysis provided explanations and helped to understand the results of the previous part.

The various correlations, more precisely Spearman coefficient (sustainability vs. MSI, sustainability vs. training, sustainability vs. communication, sustainability vs. participation in decision-making, sustainability vs. climate of continuous improvement, sustainability vs. continuous improvement's results, sustainability vs. involvement, sustainability vs. satisfaction, sustainability vs. human resources management, sustainability vs.
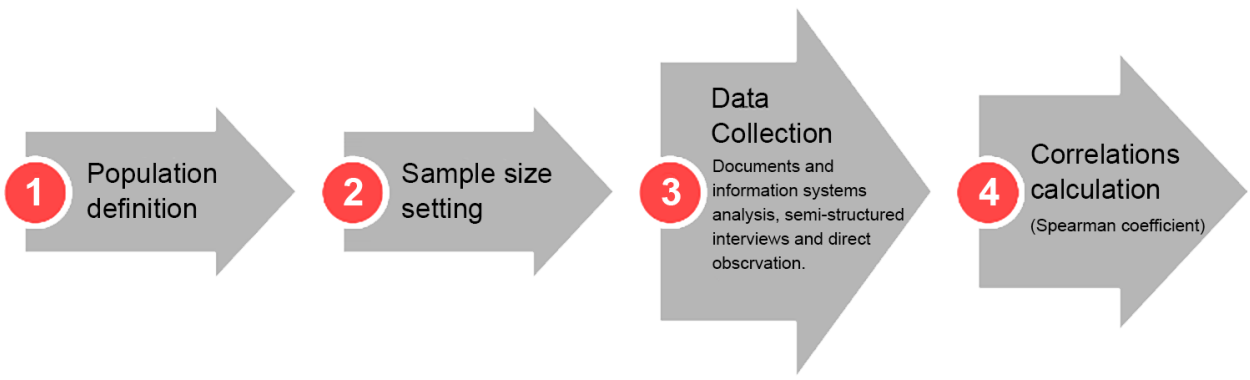

Figure 1. Data collection procedure. 
trust) were then calculated, as well as Cronback alpha coefficient, using the Statgraphics software.

\section{Results}

To find a possible correlation between lean-based improvement and musculoskeletal injury, an estimator of sustainability " $S$ " based on interviews and observations for three to six months after the continuous improvement initiative was devised. This parameter defines the extent to which the changes implemented were maintained and it is rated on a scale of 1 to 5 .

$$
S=\frac{\sqrt{S_{\text {interview }}^{2}+S_{\text {observation }}^{2}}}{2}
$$

$S_{\text {interviews }}$ is the component of the variable $S$ derived from interviews. It represents the answer to the question "Did the changes made by previous Lean events lasted in time?" Its value was assessed on a scale of 1 to 5 , where 1 represents "Strongly agree" and 5 "Strongly disagree".

$\mathrm{D}_{\text {observations }}$ is the component of the variable $\mathrm{S}$ derived from observations of continuous improvement workshops and documentation systems analysis. Its value was assessed on a scale of 1 to $5 . D_{\text {observations }}$ takes value 1 when all changes are maintained, 2 most of changes are maintained, 3 when only few changes are maintained, 4 when no changes are maintained, and five represent a worse condition than that before the change (degradation).

The prevalence of MSI was estimated on the basis of four elements identified in the answers to four questions in both surveys: MSI-related pain experienced, perception of the practice of job rotation, perception of the impact of organizational changes on MSI, and monitoring of OHS improvements.

Based on the Spearman coefficient ( $r h o=0.6929, \mathrm{p}=0.0009$ ), the bivariate relationship between sustainability and MSI is significant (see Table 1). Furthermore, the positive sign indicates that these variables are proportional. However, since sustainability was defined with an inverse scale $(1=$ maximal durability and $5=$ minimal $)$, we are looking at inverse proportionality. This indicates that the less sustainable the improved result is, the greater is the prevalence of musculoskeletal injury in the areas involved in the improvement. A correlation coefficient close to 0.7 suggests that there are counterexamples to the relationship. Indeed, some participants working in areas where the improvement was not sustainable reported no sign of MSI. Similarly, some participants having real MSI problems (mostly work-related) have always worked in areas where improvements were maintained beyond six months. The strong correlation nevertheless suggests a possible link between improvement sustainability and MSI.A correlation (see Table 1 , rho $=0.7107, \mathrm{p}=0.0007$ ) was found between the sustainability of lean-based improvements and communication of exhaustive information concerning lean improvements. More precisely, communication-wise, our study focused on the information transmitted during a lean intervention: motives, objectives, time scale, role of participants and impacts on each participant's responsibilities. Training, participation 
Table 1. Spearman correlation index between improvement sustainability and variables.

\begin{tabular}{|c|c|c|c|}
\hline & Rho & Sample size & Error $(\mathrm{p})$ \\
\hline Sustainability of lean-based improvements vs. prevalence of MSI & 0.6929 & 24 & 0.0009 \\
\hline Sustainability of lean-based improvements vs. lean training & 0.8603 & 5 & 0.0853 \\
\hline Sustainability of lean-based improvements vs. communication & 0.7107 & 24 & 0.0007 \\
\hline $\begin{array}{l}\text { Sustainability of lean-based improvements vs. training vs. } \\
\text { participation in decision-making }\end{array}$ & 0.1268 & 24 & 0.5431 \\
\hline $\begin{array}{l}\text { Sustainability of lean-based improvements vs. climate of } \\
\text { continuous improvement }\end{array}$ & -0.1933 & 24 & 0.3540 \\
\hline $\begin{array}{l}\text { Sustainability of lean-based improvements vs. } \\
\text { improvement's results }\end{array}$ & 0.2010 & 24 & 0.3350 \\
\hline Sustainability of lean-based improvements vs. involvement & 0.2359 & 24 & 0.2579 \\
\hline Sustainability of lean-based improvements vs. satisfaction & -0.1181 & 24 & 0.5710 \\
\hline $\begin{array}{c}\text { Sustainability of lean-based improvements vs. human } \\
\text { resources management }\end{array}$ & 0.2979 & 24 & 0.1531 \\
\hline Sustainability of lean-based improvements vs. trust & -0.0857 & 24 & 0.6809 \\
\hline
\end{tabular}

in decision-making, climate of continuous improvement, continuous improvement's results, involvement, satisfaction, human resources management and trust showed a low correlation with the sustainability of lean-based improvements. The reliability of the different sections of the questionnaire used in the semi-structured interviews is shown in Table 2. The Cronbach alpha coefficient is calculated generally to measure the internal consistency of a measurement comprising several elements. The majority of the scales used in this study had good reliability with a coefficient greater than 0.70 [22]. The most striking exception was for the "training" section, which had a reliability of 0.13 . Items in this section targeted employees who had participated in continuous improvement projects and who evaluated the training received during these events. In some cases, general instruction on lean manufacturing was provided throughout the company before or after events. This was not evaluated in the present study. Participants' answers could concern any of these training sessions, thus creating some inconsistency. The reliabilities of "satisfaction", "human resources management" and "trust" were below 0.7 . The relative inconsistency associated with these elements is likely due to their subjective nature and the subjective factor in almost all of the questions. They reflect employee appreciation of the employers and the work environment. This appreciation can be biased upward, for example when the reasons for the present study were not understood. The employee might have believed that his or her own performance was being evaluated and therefore consciously avoided making any pejorative statement about the employer. In other cases, the employee might have been expressing dissatisfaction with the experience of the event while otherwise experiencing overall job satisfaction. 
Table 2. Cronbach alpha coefficients.

\begin{tabular}{cc}
\hline Survey 2 Themes & Cronbach Alpha coefficient \\
\hline Sustainability of lean improvements & 0.94 \\
Training & 0.67 \\
Communication & 0.13 \\
Participation in decision-making & 0.95 \\
Climate of continuousimprovement & 0.80 \\
Continuousimprovement'sresults & 0.74 \\
Involvement & 0.75 \\
Satisfaction & 0.77 \\
Humanresources management & 0.21 \\
Trust & 0.18 \\
\hline
\end{tabular}

\section{Discussion}

This study targeted the case of a single manufacturing company in the aerospace field. It is therefore not possible to generalize the findings to all manufacturing companies. Although we can say that the results do not refute the research hypothesis, the study of several business cases would be required to confirm the hypothesis. We cannot presume that the company studied represents a perfect model of integration of OHS and lean manufacturing. Integration of OHS and lean manufacturing in this company was not systematic and did not always follow the same approach. In the ideal case, the company would have integrated OHS into all continuous improvement activities using the same structured approach. It is therefore difficult to evaluate the success or failure of this integration based solely on the example of the participating company. According to Kerr and Jackofsky [23], it is during the early stages of the implementation of a lean-based improvement that the objectives of the changes must be aligned with the organization's goals. The company under study does not always follow this approach when choosing a lean-inspired course of action. Over $60 \%$ of the time, the continuous improvement initiative is a response to a request made by managers to improve a situation that they consider problematic. Due to the subjective judgment of the seriousness of the situation and to the rarity of objective data, important aspects of the problem may be overlooked. A structure that quantifies the performance of each entity of a company and points out the connections between them would provide better definition of the objectives of lean-inspired initiatives and more effective monitoring of the results. Considering the lean interventions observed in this study, it is difficult to say that one lean technique is superior to another in terms of the sustainability of the results, especially given that lean techniques are used differently from one company to another. Laraia et al. [24] suggested that both the effectiveness and the sustainability of lean- 
based improvements could be increased if lean tools were simpler and easier to use. Other research has shown that lean initiatives do not yield the expected results if only some of the tools are used [25] (These claims could not be examined in the present study). However, due to their diversity and variants, it is not always possible to bring the same collection of tools to a given company. Furthermore, it should be noted that the choice of one lean technique or another does not guarantee that the organization will achieve its improvement goals if it has not already adopted the principles of the JIT philosophy [25]. The correlation between the sustainability of improvements achieved through Lean initiatives and the incidence of MSI is attributable to the fact that improvements in OHS, due to the nature of business, require consistent efficiency and stable performance over the short-to-medium term if a risk-free environment is to be maintained. Having said this, measuring improved OHS performance at a given point in time does not ensure that a true improvement has been achieved. The true test is the sustainability of the new level of performance [26]. The literature review did not reveal any previous attempts to associate lean improvement sustainability with the incidence of MSI. The results of the present study cannot therefore be appreciated with respect to previously published results of similar nature. Herein lays the originality of this research. On the other hand, if we look for attempts to determine the impact of lean manufacturing on OHS, the results are much more abundant, and the confrontation of our findings with existing knowledge becomes possible. Studies on the integration of OHS into continuous improvement activities have generally concluded that the effects on worker wellbeing may be positive or negative [1] [2] [3] [4] [7]. These studies considered lean manufacturing as a single model of technical operations management that is reproduced identically in all businesses. In the present study, the unsustainability of lean improvements was found responsible for the failure of the integration of lean into OHS issues. However, we do not conclude that this failure is inherent in lean manufacturing itself, but rather due to an inappropriate approach to the implementation of this tool in this particular business. Our conclusion is original insofar as several studies conclude that lean manufacturing, due to its mindset and tools, is by its nature detrimental to OHS [1] [2] [3] [7]. However, a few recent studies do suggest that the reputation of lean manufacturing suffers primarily from the use of its tools in a context of rapid problem solving without proper association with a policy of continuous improvement or a JIT culture [5]. Based on Spearman correlation and Cronbach Alpha coefficients, communication (of the lean techniques to be used, the project start and finish dates, the objectives behind the project, the role of each participant in the project and the possible impact of the project on employee responsibilities) was found strongly associated with the sustainability of the results of continuous improvement activities. This strong correlation is attributable to heightened employee awareness and commitment early in the process of implementing and monitoring the improvements [24] [25]. It should be noted that communication as assessed via the surveys conducted during this study did not take into account the communication of the project results. It is entirely possible that disclosure of this information has a significant impact on the sustai- 
nability of improvements. Participation of company employees in decision-making might improve the sustainability of the results. This factor is fully effective only when all of the employees involved in the changes being made take part in the decision process. Several studies suggest that placing employee involvement in company choices at the heart of the lean process is the most productive approach [27]-[32]. Furthermore, even if our sample size is small, the participants with experience in lean manufacturing consistently mentioned a strong relation between participation in decision-making and the sustainability of the improvements. This likely reflects the company's tendency not to consult employees outside the lean project when it comes to making decisions concerning improvements to their working conditions. Our analysis suggests that the nature of the immediate results of the lean initiative might not affect their sustainability. This implies that simply having more positive than negative results at the end of a lean project will not increase the sustainability of the improvement. However, the literature is inconsistent on the influence of immediate results on the sustainability of lean-based improvements [33] [34] [35].

Finally, a climate of continuous improvement [36], good communication of the challenges to be met and the details of a change implemented by management should encourage participation in decision-making. Participation in decision-making is an effective way to gather ideas on improvement and to identify other helpful changes. This is suggested in a dissertation by Burch [32], who emphasized the importance of soliciting employee suggestions (participants and non-participants in improvement projects) during communication of the progress achieved following the completion of projects. According to the findings of the present study, this should contribute to maintaining a routine of continuous improvement within groups.

\section{Conclusions}

The integration of OHS into continuous improvement activities is achieved through its systematic consideration in the course of implementing the proposed changes. The purpose of this project was to define a better approach to the implementation of lean principles to improve this integration. To achieve this, we examined the hypothesis that integration of OHS into continuous improvement activities was unsuccessful when these activities themselves suffered from unsustainability issues. The main objective is to document the effect that non-sustainability of improvements achieved by applying lean principles has on OHS, and a statistical study was conducted in a manufacturing company to find a possible correlation between the sustainability of the results of six continuous improvement interventions and the development of MSI among employees affected by the changes (participants and non-participants in the projects). This research revealed a strong association between these variables. The qualitative component of this study supported this association and brought to light new elements. For example, observation of projects during and after the intensive days (Kaïzen events) and analysis of company documentation revealed that the lean improvement process in this company differed from that presented in literature and even varied from one project to another. 
A secondary objective, which arose in the course of the study, was to identify elements that might improve the sustainability of the results of continuous improvement initiatives. The same statistical method was used to reveal possible associations. At the end of the study, communication was identified as crucial in any attempt to increase the sustainability of lean-based improvements.

Finally, more case studies with larger sample sizes are needed to generalize the findings and constitute future research directions.

\section{References}

[1] Parker, S. (2003) Longitudinal Effects of Lean Production on Employee Outcomes and the Mediating Role of Work Characteristics, Journal of Applied Psychology, 88, 620-634. http://dx.doi.org/10.1037/0021-9010.88.4.620

[2] Landsbergis, P.A., Cahill, J. and Schnall, P.L. (1999) The Impact of Lean Production and Related New Systems of Work Organization on Worker Health. Journal of Occupational Health Psychology, 4, 108-130. http://dx.doi.org/10.1037/1076-8998.4.2.108

[3] Liker, J.K. and Hoseus, M. (2010) Human Resource Development in Toyota Culture. International Journal of Human Resources Development and Management, 10, 34-50. http://dx.doi.org/10.1504/IJHRDM.2010.029445

[4] Saurin, T.A. and Ferreira, C.F. (2009) The Impacts of Lean Production on Working Conditions: A Case Study of a Harvester Assembly Line in Brazil. International Journal of Industrial Ergonomics, 39, 403-412. http://dx.doi.org/10.1016/j.ergon.2008.08.003

[5] Tortorella, G.L. and Fogliatto, F.S. (2014) Method for Assessing Human Resources Management Practices and Organisational Learning Factors in a Company Under Lean Manufacturing Implementation. International Journal of Production Research, 52, 4623-4645.

[6] Hasle, P. (2014) Lean Production-An Evaluation of the Possibilities for an Employee Supportive Lean Practice. Human Factors and Ergonomics in Manufacturing \& Services Industries, 24, 40-53. http://dx.doi.org/10.1002/hfm.20350

[7] ANACT (2013) Les méthodes d'organisation du travail: le lean en question. Note de positionnement, Paris.

[8] Nishiyama, K. and Johnson, J.V. (1997) Karoshi-Death from Overwork: Occupational Health Consequences of Japanese Production Management. International Journal of Health Services, 27, 625-641. http://dx.doi.org/10.2190/1JPC-679V-DYNT-HJ6G

[9] Bakker, A.B., Demerouti, E., De Boer, E. and Schaufeli, W.B. (2003) Job Demands and Job Resources as Predictors of Absence Duration and Frequency. Journal of Vocational Behavior, 62, 341-356. http://dx.doi.org/10.1016/S0001-8791(02)00030-1

[10] Demerouti, E., Bakker, A.B., Nachreiner, F. and Schaufeli, W.B. (2000) A Model of Burnout and Life Satisfaction among Nurses. Journal of Advanced Nursing, 32, 454-464. http://dx.doi.org/10.1046/j.1365-2648.2000.01496.x

[11] Demerouti, E., Bakker, A.B., Nachreiner, F. and Schaufeli, W.B. (2001) The Job DemandsResources Model of Burnout. Journal of Applied Psychology, 86, 499-512. http://dx.doi.org/10.1037/0021-9010.86.3.499

[12] Bateman, N. (2005) Sustainability: The Elusive Element in Process Improvement. International Journal of Operations and Production Management, 25, 261-276. http://dx.doi.org/10.1108/01443570510581862

[13] Bateman, N. and David, N. (2002) Process Improvement Programs: A Model for Assessing 
Sustainability. International Journal of Operations and Production Management, 22, 515526. http://dx.doi.org/10.1108/01443570210425156

[14] Glover, W.J., Farrin, J.A., Van Aken, E.M. and Doolen, T.L. (2011) Critical Success Factors for the Sustainability of Kaizen Event Human Resource Outcomes: An Empirical Study. International Journal of Production Ergonomics, 132, 197-213.

[15] Farris, J.A., Van Aken, E.M., Doolen, T.L. and Worley, J.M. (2009) Critical Success Factors for Human Resource Outcomes in Kaizen Events: An Empirical Study. International Journal of Production Economics, 117, 42-65.

[16] Roome, N., Ed. (1998) Sustainability Strategies for Industry: The Future of Corporate Strategy. Island, Washington DC.

[17] Kaye, M. and Anderson, R. (1999) Continuous Improvement: The Ten Essential Criteria. International Journal of Quality and Reliability Management, 16, 485-506. http://dx.doi.org/10.1108/02656719910249801

[18] Bernard, B.P., Ed. (1997) Musculoskeletal Disorders and Workplace Factors: A Critical Review of Epidemiologic Evidence for Work-Related Musculoskeletal Disorders of the Neck, Upper Extremity, and Low Back. U.S. Department of Health and Human Services, Cincinnati.

[19] Womack, J.P., Jones, D.T. and Roos, D. (1991) The Machine that Changed The World. Free Press, New York.

[20] Womack, J.P., Jones, D.T. and Roos, D. (2007) The Machine that Changed the World. Macmillian, New York.

[21] Landsbergis, P.A., Schnall, P.L., Dietz, D.K., Warren, K., Pickering, T.G. and Schwartz, J.E. (1998) Job Strain and Health Behaviors: Results of a Prospective Study. American Journal of Health Promotion, 12, 237-245. http://dx.doi.org/10.4278/0890-1171-12.4.237

[22] Schmitt, N. (1996) Uses and Abuses of Coefficient Alpha. Psychological Assessment, 8, 350353. http://dx.doi.org/10.1037/1040-3590.8.4.350

[23] Kerr, J. and Jackofsky, E. (1989) Aligning Managers with Strategies: Management Development versus Selection. Strategic Management Journal, 10, 157-170. http://dx.doi.org/10.1002/smj.4250100712

[24] Laraia, A.C., Moody, P.E. and Hall, R.W. (1999) The Kaizen Blitz: Accelerating Breakthroughs in Productivity and Performance. The Association for Manufacturing Excellence, New York.

[25] Liker, J.K. (2004) The Toyota Way: 14 Management Principles from the World Greatest Manufacturer. McGraw-Hill, New York, 352 p.

[26] Booth, T. and Booth, W. (1993) Parenting with Learning Difficulties: Lessons for Practitioners. British Journal of Social Work, 23, 459-480. http://dx.doi.org/10.1093/bjsw/23.5.459

[27] Longoni, A. and Cagliano, R. (2015) Cross-Functional Executive Involvement and Worker Involvement in Lean Manufacturing and Sustainability Alignment. International Journal of Operations \& Production Management, 35, 1332-1358. http://dx.doi.org/10.1108/IJOPM-02-2015-0113

[28] Stahl, A.-C.F., Gustavsson, M., Karlsson, N., Johansson, G. and Ekberg, K. (2015) Lean Production Tools and Decision Latitude Enable Conditions for Innovative Learning in Organizations: A Multilevel Analysis. Applied Ergonomics, 47, 285-291. http://dx.doi.org/10.1016/j.apergo.2014.10.013

[29] Banker, R., Potter, G. and Schroeder, R. (1993) Reporting Manufacturing Performance 
Measures to Workers: An Empirical Study. Journal of Management Accounting Research, 5, 33-53.

[30] Hall, R.W. (1987) Attaining Manufacturing Excellence. Business One Irwin, Homewood.

[31] Schonberger, R.J. (1982) Some Observations on the Advantages and Implementation Issues of Just-in-time Production Systems. Journal of Operations Management, 3, 1-11. http://dx.doi.org/10.1016/0272-6963(82)90017-1

[32] Burch, M.K. (2008) Lean Longevity Kaizen Events and Determinants of Sustainable Improvement. Dissertation, Isenberg School of Management, University of Massachusetts, Amherst.

[33] Keating, E., Oliva, R., Repenning, N., Rockart, S. and Sterman, J. (1999) Overcoming the Improvement Paradox. European Management Journal, 17, 120-134. http://dx.doi.org/10.1016/S0263-2373(98)00072-3

[34] Kotter, J. (1995) Leading Change: Why Transformation Efforts Fail. Harvard Business Review, 73, 59-67.

[35] Doolen, T.L., Van Aken, E.M., Farris, J.A., Worley, J.M. and Huwe, J. (2008) Kaizen Events and Organizational Performance: A Field Study. International Journal of Productivity and Performance Management, 57, 637-658. http://dx.doi.org/10.1108/17410400810916062

[36] Robson, L.S., Amick, B.C., Moser, C., Pagell, M., Mansfield, E., Shannon, H.S., Swift, M.B., Hogg-Johson, S., Cardoso, S. and South, H. (2016) Important Factors in Common Organizations Making Large Improvement in OHS Performance: Results of an Exploratory Multiple Case Study. Safety Science, 86, 211-227. http://dx.doi.org/10.1016/j.ssci.2016.02.023

\section{Submit or recommend next manuscript to SCIRP and we will provide best service} for you:

Accepting pre-submission inquiries through Email, Facebook, LinkedIn, Twitter, etc.

A wide selection of journals (inclusive of 9 subjects, more than 200 journals)

Providing 24-hour high-quality service

User-friendly online submission system

Fair and swift peer-review system

Efficient typesetting and proofreading procedure

Display of the result of downloads and visits, as well as the number of cited articles

Maximum dissemination of your research work

Submit your manuscript at: http://papersubmission.scirp.org/

Or contact ajibm@scirp.org 